Boise State University

ScholarWorks

Biology Faculty Publications and Presentations

Department of Biological Sciences

5-1-2019

Evolution of the Caribbean Species of Columnea (Gesneriaceae) with an Emphasis on the Jamaican Species

James F. Smith

Boise State University

Maggie T.-Y. Ooi

Boise State University

Lacie J. Schulte

Boise State University

Keron C. St.E. Campbell

Institute of Jamaica

Judeen Meikle

Institute of Jamaica

See next page for additional authors 
Authors

James F. Smith, Maggie T.-Y. Ooi, Lacie J. Schulte, Keron C. St.E. Campbell, Judeen Meikle, and John L. Clark 


\title{
EVOLUTION OF THE CARIBBEAN SPECIES OF COLUMNEA (GESNERIACEAE) WITH AN EMPHASIS ON THE JAMAICAN SPECIES
}

\author{
James F. Smith, ${ }^{1, *}$ Maggie T.-Y. Ooi, ${ }^{*}$ Lacie J. Schulte,* Keron C. St. E. Campbell, † Judeen Meikle, † and John L. Clark‡ \\ *Department of Biological Sciences, Boise State University, 1910 University Drive, Boise, Idaho 83725, USA; +Natural History \\ Museum of Jamaica, Institute of Jamaica, 10-16 East Street, Kingston, Jamaica; and ¥Science Department, \\ the Lawrenceville School, 2500 Main Street, Lawrenceville, New Jersey 08648, USA \\ Editor: Oscar Rocha
}

\begin{abstract}
Premise of research. Biogeography has improved understanding of evolution and diversification of organisms on both continental and island systems. One complicated island group in terms of geological history and biogeographic pattern is the Caribbean island system. A comparison across taxonomic groups does not result in overarching patterns for this group of islands. Columnea has the greatest number of species endemic to the Caribbean for any genus in Gesneriaceae that is not mostly endemic to the Caribbean with 16 species. Thirteen of these species are found on Jamaica, the remaining three each endemic to Cuba, Hispaniola, and Puerto Rico. In addition, populations of Columnea sanguinea and Columnea scandens are known from both mainland and multiple Caribbean islands. We investigate the pattern of evolution in Caribbean species of Columnea and attempt to explain the large number of species found on the island of Jamaica relative to the other islands. We explicitly test whether Caribbean species of Columnea are monophyletic and whether the 13 species endemic to Jamaica are a monophyletic group. This genus can help understand biogeographic patterns and modes of speciation in the Caribbean.
\end{abstract}

Methodology. We sampled all Caribbean species of Columnea using DNA sequence data and phylogenetic methods to understand the pattern of diversity to determine whether multiple or single introductions could explain the diversity on the Caribbean islands.

Pivotal results. The Caribbean species do not form a monophyletic group. The Jamaican species are monophyletic, and the endemic Cuban species, Columnea tincta, is sister to 12 of the Jamaican species, with Columnea pubescens sister to C. tincta + remaining Jamaican species. Most Jamaican species share similar corolla morphologies to section Columnea. Although never recovered as part of section Columnea, approximately unbiased tests cannot reject a sister group relationship of the Jamaican/Cuban endemic clade to section Columnea but can reject inclusion in section Columnea.

Conclusions. The high diversity of Columnea in the Caribbean is due to the disproportionate number of species on Jamaica, but there is no obvious explanation for the radiation on this island, despite considering island size, topography, pollinators, and dispersers. The large number of species could be attributed to over-splitting on Jamaica, but even if a narrower concept were followed, and four of the species were combined as varieties of Columnea hirsuta as earlier taxonomy had predicted, the number of morphologically distinctive species would still be nine and much greater than that of the other islands. Our data also indicate that C. hirsuta sensu lato is not monophyletic.

Keywords: diversification, island biogeography, key innovation, speciation, topography, Columnea.

Online enhancement: supplemental figure.

\section{Introduction}

The distribution of biological diversity across the planet, including how it got to be where it is and why it persists there,

1 Author for correspondence; email: jfsmith@boisestate.edu.

Manuscript received September 2018; revised manuscript received January 2019; electronically published April 3, 2019. has been a puzzle facing naturalists that precedes the theory of natural selection (Humboldt 1805; Schouw 1823; Brongniart 1828; Swainson 1835; Darwin 1839; Sclater 1858) and has continued to the present day (Huxley 1868; Wallace 1860, 1869, 1876, 1880; MacArthur and Wilson 1963, 1967; Carlquist 1965; Brundin 1972; Raven and Axelrod 1974; Platnick and Nelson 1978; Rosen 1978; Nelson and Platnick 1981; Ronquist and Cannatella 1997; Ree and Smith 2008; Yu et al. 2010; Matzke 2013). The insights that arose after proposing evolution 
by natural selection clearly drove the study of biogeography into more specific questions. The advancement of island biogeography theory (MacArthur and Wilson 1963, 1967; Carlquist 1965) and molecular systematics (Hillis and Moritz 1990), coupled with new analytical tools (Ronquist and Cannatella 1997; Ree and Smith 2008; Yu et al. 2010; Matzke 2013), has resolved many questions that puzzled the first naturalists about why species are where they are and how they came to have that distribution.

In the past 20-25 years there has been a growing interest in the evolution of biological diversity on islands using phylogenetic approaches. Major advancements in our understanding of the origins and evolution of the Hawaiian flora have occurred with a new and better understanding that this group of isolated volcanic islands has also been biologically isolated, with fewer source introductions for many groups than had previously been assumed (Baldwin et al. 1990, 1991; Givnish et al. 1995; Gillespie and Croom 1995; Tarr and Fleischer 1995; Gemmill et al. 2002; Cronk et al. 2005; Clark et al. 2008), and that speciation and diversification within the islands has been the explanation for the tremendous diversity. The distance from source populations on Hawaii certainly matches MacArthur and Wilson's $(1963,1967)$ prediction that diversity on the island would result from few colonizers. Other islands not as isolated as the Hawaiin chain have also been the focus of studies on evolutionary biogeography, and they include New Zealand (Trewick 1997; Wagstaff and Garnock-Jones 1998; von Hagen and Kadereit 2001; Winkworth et al. 2002; Woo et al. 2011), Madagascar (Buerki et al. 2008; Callmander et al. 2016; Gostel et al. 2016, 2016; Bauret et al. 2017), and New Caledonia (Smith et al. 2007; Swenson et al. 2007; Ladiges and Cantrill 2007; Woo et al. 2011).

The present distance from the mainland and size of islands has been critical for interpreting many of the patterns seen with island biodiversity (MacArthur and Wilson 1963, 1967). However, geological advances have allowed even greater interpretation of patterns than MacArthur and Wilson $(1963,1967)$ could have predicted. Knowledge that some islands were parts of continents, that others are volcanic in origin, that none have been the same size or distance from mainlands throughout their existence, and that some have been completely submerged during their histories has altered how we interpret the evolution of biological diversity in island systems (Cracraft 1973; Raven and Axelrod 1974; Molnar et al. 1975; Iturralde-Vinent and MacPhee 1999; Campbell and Landis 2003; Yoder and Nowak 2006; Grandcolas et al. 2008; Heads 2008; Whitaker et al. 2008).

A group of islands where biogeography has clearly benefited from a better understanding of geology is the Caribbean (Iturralde-Vinent and MacPhee 1999). The geological history of this group of islands is complicated and unlikely to be completely resolved at present. However, better knowledge of the origins of many of the islands and their histories of connections in the past has greatly enhanced our ability to interpret distributions of the biota, mainland sources, and likelihood that evolution and diversification took place in situ. The concept of GAARlandia (Iturralde-Vinent and MacPhee 1999), where the Greater Antilles and Aves Ridge were once connected to mainland South America, has been an important explanation for much of the diversity in the Caribbean islands, and even when patterns do not match the GAARlandia hypothesis it is an important null model against which to test. The biogeography of the Caribbean reflects the complexity of the geology, fluctuating sea levels, and proximity of subsets of the islands to North America, Central America, and South America. The Antilles are a major wintering ground for many Nearctic migrants (Wunderle and Waide 1993) as well as being a flyway for some bird species that migrate from South America to North America and back, although most studies indicate that the flights are made without any stopovers (SELVA 2017).

The Gesneriaceae are diverse in the Neotropics in general (Weber et al. 2013), with a large diversity in the Caribbean. Four genera are mostly endemic to the Caribbean (Gesneria, Rhytidophyllum, Pheidonocarpa, and Bellonia; Skog 1976; Roalson et al. 2008; Weber et al. 2013; Möller and Clark 2013), but an additional 13 genera have at least one to five species on the Caribbean islands (excluding the Old World-introduced Saintpaulia ionantha $\mathrm{H}$. Wendl.) with Columnea having 18 species distributed among the islands (Acevedo-Rodriguez and Strong 2017), 16 of which are endemic to a single island (Morley 1974). The remaining two species, Columnea sanguinea and Columnea scandens, are relatively widespread and found on multiple islands as well as mainland areas (Morley 1974; AcevedoRodriguez and Strong 2017). The endemic species are Columnea ambigua from Puerto Rico, Columnea domingensis endemic to Hispaniola, Columnea tincta endemic to Cuba, and 13 species endemic to Jamaica (Columnea argentea, Columnea brevipila, Columnea fawcettii, Columnea grisebachiana, Columnea harrisii, Columnea hirsuta, Columnea hispida, Columnea proctorii, Columnea pubescens, Columnea repens, Columnea rutilans, Columnea subcordata, and Columnea urbanii). The large number of species of Columnea can in part be explained by the fact that Columnea is the most species-rich genus of Gesneriaceae in the Neotropics, but the high diversity of Columnea in Jamaica is an anomaly. Aside from the four genera mostly endemic to the Caribbean, Besleria, another large Neotropical genus in terms of the number of species, follows Columnea with five species distributed in the Caribbean. All but Besleria lutea are endemic to the Lesser Antilles, and B. lutea is found on many Caribbean islands of both the Greater and Lesser Antilles as well as South America (Acevedo-Rodriguez and Strong 2017).

Based on previously published phylogenetic analyses, the five Caribbean species of Columnea that have been sampled are in three different clades (Smith et al. 2013; Schulte et al. 2014, 2015). Columnea ambigua and C. domingensis are sister to each other and included in section Angustiflorae. This section was described by Schulte et al. (2014) to include the species that Smith (1994) had included in section Stygnanthe, but Smith's (1994) section Stygnanthe was not recovered as monophyletic (Smith et al. 2013). Both sections Angustiflorae and Stygnanthe are characterized by relatively small corollas with a radial to subradial limb (fig. 1A). Although most morphological traits in the species of the two sections have a broad degree of overlap, the ratio of corolla tube to corolla lobe can be diagnostic for the two sections. Columnea grisebachiana has a corolla similar to that of the species of these two sections and a corolla-tube-tolobe ratio that would place the species in section Angustiflorae (fig. 1D), but preliminary unpublished results from Schulte et al. (2014) did not place C. grisebachiana in this section. Columnea scandens (fig. 1G) is included in section Columnea and is the type species for the genus. This clade is distinctive in having a long corolla tube that is strongly bilaterally symmetrical with 

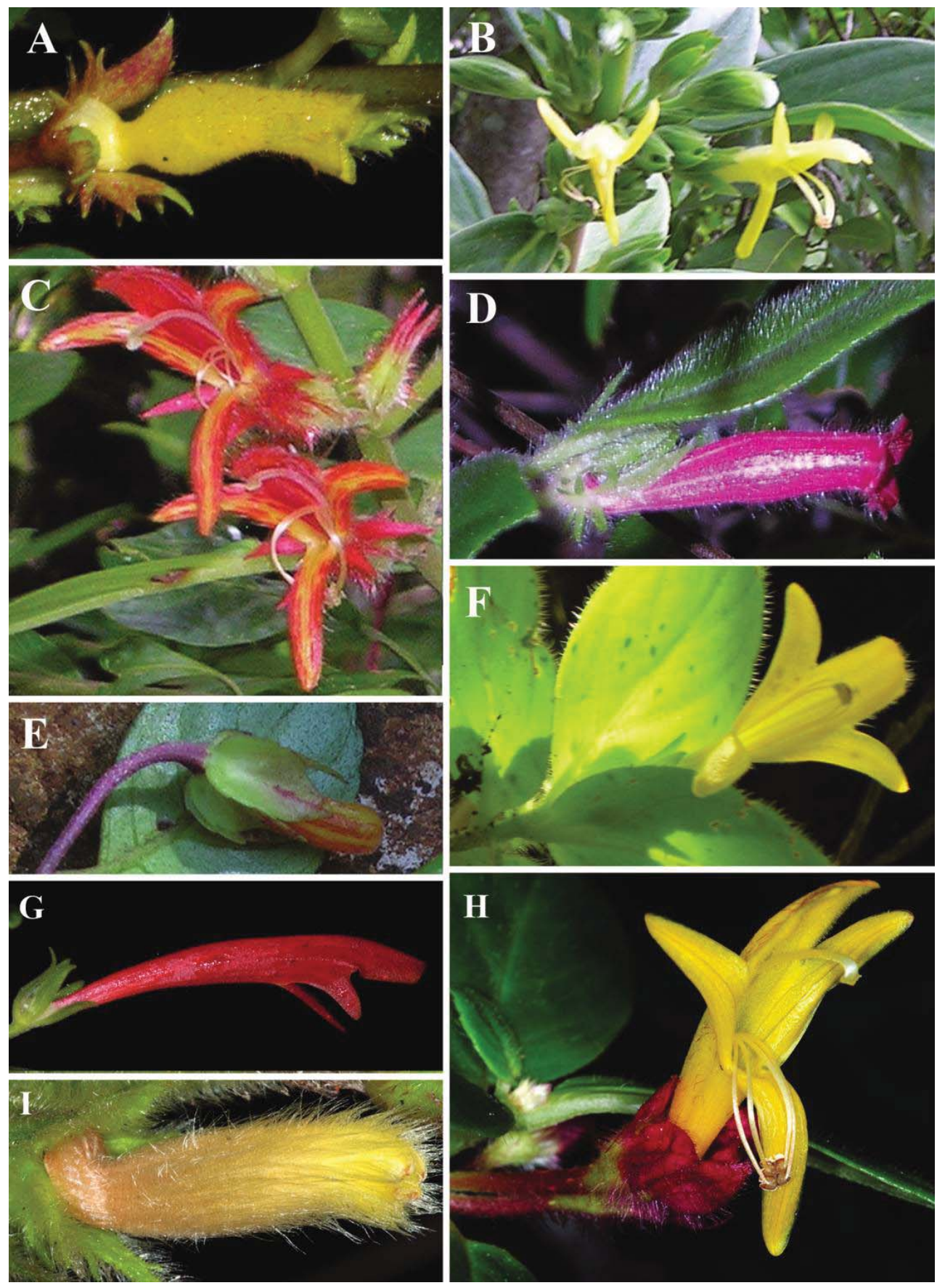

Fig. 1 Images of Caribbean species of Columnea. A, Columnea ambigua from Puerto Rico. B-F, Jamaican endemic species. B, Columnea argentea. C, Columnea fawcettii. D, Columnea grisebachiana. E, Columnea repens (in bud). F, Columnea urbanii. G, Columnea scandens. H, Columnea tincta from Cuba. I, Columnea sanguinea. Photographs B-F by J. F. Smith and G-I by J. L. Clark.

the upper two corolla lobes connate and forming a galea, two lateral corolla lobes, and a fifth lower lobe that is often reflexed backward from the corolla opening (fig. $1 G$ ). This section has been supported as monophyletic in many previous studies (Smith et al. 2013; Schulte et al. 2014, 2015).
The endemic Jamaican species of Columnea were originally described in three genera-Alloplectus, Pterygoloma, and Columnea - with a complicated history of moving several of the species across the three genera. Columnea repens was initially described as Alloplectus repens Hook., transferred to Ptery- 
goloma (P. repens [Hook.] Hanst.), then treated as Columnea section Pterygoloma (Fritsch 1894), and eventually moved to the genus Ortholoma (Wiehler 1973). Columnea pubescens followed a nearly reverse path, having been initially described as Pterygoloma (P. pubescens Griseb.), then to Alloplectus (A. pubescens [Griseb.] Fawc.), to Ortholoma (Wiehler 1973), and to Trichantha (Wiehler 1975). Finally, C. grisebachiana was initially described as Pterygoloma, transferred to Alloplectus (A. grisebachiana [Kuntze] Urb.) and to section Pterygoloma (Morley 1974), to Ortholoma (Wiehler 1973), and to Trichantha (Wiehler 1975). All three species were eventually transferred to Columnea (or back) and considered members of section Ortholoma within Columnea (Kvist and Skog 1992), although section Ortholoma was considered artificial because it was not monophyletic (Smith et al. 2013). As mentioned above for C. grisebachiana, C. pubescens and C. repens have relatively small corolla tubes and radial to subradial limbs (fig. $1 D, 1 E$ ). In contrast, the remaining 10 species of Columnea endemic to Jamaica all have corollas that match the morphology seen in section Columnea (fig. $1 B, 1 C, 1 F, 1 G$ ) and have traditionally been placed in this section without controversy (Morley 1974; Wiehler 1983). The circumscription of these 10 species has varied over time, with five of the currently recognized species all considered varieties or forms of C. hirsuta (C. fawcettii, C. harrisii, C. proctorii, and C. urbanii). If a more conservative species concept were followed, combining these five species into one, there would still be nine species on Jamaica alone. Smith et al. (2013) included two Jamaican endemic species in their analyses: C. brevipila from section Columnea and C. repens from section Ortholoma. The two species were sister to each other, implying that the Jamaican endemic species may not be part of two different sections and instead may form a monophyletic group. Insufficient taxon sampling at that time prevented further investigation of this hypothesis.

In the present study, we use molecular phylogenetic analyses to investigate the evolution of Columnea species in the Caribbean with a focus on the large number of species in Jamaica. Many previous studies that have elucidated the biogeography of other taxonomic groups in the Caribbean have recovered a variety of patterns with dispersals from North, Central, and South America; multiple independent introductions of genera into different islands; a single introduction; or a combination of parts of the above (Hedges and Burnell 1990; Seutin et al. 1994; Salzman and Judd 1995; Peck 1997; Schubart et al. 1998; Fritsch 2003; Fritsch and McDowell 2003; Negron-Ortiz and Watson 2003; Joseph et al. 2004; Santiago-Valentin and Olmstead 2004; Hedges 2006; Heinicke et al. 2007; Acevedo and Strong 2008; Roalson et al. 2008; Roncal et al. 2008; Van Ee and Berry 2009; Crews and Gillespie 2010; Gauthier 2010; Oneal et al. 2010; Rodríguez et al. 2010; Matos-Moraví et al. 2014; Irimia et al. 2015; Weaver et al. 2016). Like the geology of the region, the biota also exhibit a complicated evolutionary history.

\section{Material and Methods}

\section{Taxon Sampling}

We sampled all species of Columnea native to the Caribbean. Columnea scandens, Columnea repens, Columnea brevipila, Columnea ambigua, and Columnea domingensis had been in- cluded in prior studies (Smith et al. 2013, 2017, 2018; Schulte et al. 2014, 2015). Fieldwork in Jamaica in 2012 allowed us to sample an additional population of C. repens as well as all other endemic Jamaican species except Columnea subcordata, which was obtained from living material at the Botanical Garden in Geneva, and Columnea pubescens. Despite several days of searching in the Blue Mountains and John Crow Mountains region of Jamaica, we were unable to relocate C. pubescens in 2012, but subsequent fieldwork by K. C. St. E. Campbell in 2018 in the John Crow Mountain region of the Blue and John Crow Mountains area resulted in the collection of C.pubescens. We included species from other clades in the genus that had been published previously (appendix; Smith et al. 2013; Schulte et al. 2014, 2015) as well as all available accessions of Columnea minor, as this species had been shown to be sister to the two sampled individuals of Jamaican Columnea species in previous analyses (Smith et al. 2013). Total sampling for this analysis is 123 individuals of Columnea, comprising 83 species. All analyses were rooted using four species of Glossoloma as the outgroup (appendix).

\section{DNA Extraction, Amplification, and Sequencing}

DNA was extracted from all samples using Qiagen Plant DNeasy mini kits (Qiagen, Valencia, CA), following the manufacturer's instructions, with the exception that incubation of the samples at $60^{\circ} \mathrm{C}$ was extended to $2 \mathrm{hr}$. Amplification of internal transcribed spacer, $r p s 16$ intron, $t r n S-\operatorname{trn} G$ spacer, $p s b A$ $\operatorname{trnH}$ spacer, $\operatorname{trn} Q-r p s 16$ spacer, and $r p l 32-$ trn $_{U A G}$ used the primers and methods of Schulte et al. (2014). We also sampled external transcribed spacers here using the primers of Baldwin and Markos (1998). Successful amplifications were determined by viewing aliquots on $1 \%$ agarose gels stained with ethidium bromide and viewed under ultraviolet illumination. All successful amplifications were purified using Exo-SAPit (Affymetrix, Cleveland, $\mathrm{OH}$ ) and shipped to GeneWiz (Plainfield, $\mathrm{NJ}$ ) for sequencing in both directions. Chromatograms were downloaded from the GeneWiz site and edited, and consensus sequences were generated from both strands using Phy-DE (Müller et al. 2010).

\section{Phylogenetic Analyses}

Sequences were aligned for each of the seven regions separately, generating indels to keep homologous sequences aligned. Ambiguous sequences and large portions of missing data were removed from the ends of all regions, and a concatenated data set for all seven regions was generated and used as the basis for all phylogenetic analyses.

Maximum parsimony (MP) and MP bootstrap (MPBS) were evaluated using PRAP2 (Müller 2004) in conjunction with PAUP* (Swofford 2002). To verify that cpDNA and nrDNA sampled regions were generating the same tree, separate MP analyses were run of the five cpDNA regions and two nrDNA regions. Maximum likelihood (ML) was assessed using RaxML (Stamatakis 2006) on the CIPRES Science Gateway (Miller et al. 2010) under the default GTR + G+I model and allowing bootstrapping to stop automatically. Consensus trees were generated and viewed in MEGA 7 (Kumar et al. 2016). The best fit model for DNA evolution was determined using jmodeltest 2.1.7 (Darriba et al. 2012) on the CIPRES Science Gateway (Miller et al. 
2010). The best model was incorporated into the DNA data set and analyzed with MrBayes 3.2 (Ronquist et al. 2012) on the CIPRES Science Gateway (Miller et al. 2010) both with and without the Beagle library, as inclusion of the library in some analyses may yield spurious results. Majority-rule consensus trees of the output were generated in PAUP*, and effective sample size (ESS) values were estimated in Tracer (Rambaut et al. 2014).

To test the strength of the support for relationships that were not recovered in the best trees, approximately unbiased (AU) tests in CONSEL (Shimodaira and Hasegawa 2001; Shimodaira 2002) were conducted comparing the best trees with constrained trees. Constraint trees included (1) all of the Jamaican/ Cuban endemic (JCE) species of Columnea sister to the clade containing species of Columnea section Columnea, (2) including the JCE species of Columnea within section Columnea as part of a polytomy, (3) constraining the JCE clade to be sister to each of the five clades that comprise the polytomy in section Columnea (fig. 2), (4) constraining all endemic Caribbean species as monophyletic, (5) constraining all Caribbean species of Columnea as monophyletic, (6) constraining Columnea sanguinea as monophyletic, both where the cultivated sample and the Caribbean samples fall in the unconstrained trees, and (7) constraining a monophyletic Columnea hirsuta s. 1. that made Columnea hirsuta, Columnea fawcettii, Columnea harrisii, Columnea proctorii, and Columnea urbanii as monophyletic with a polytomy of the species.

\section{Results}

\section{Sequencing}

DNA extraction was successful for all samples, although some regions did not amplify for all individuals (appendix), resulting in 346 new sequences generated for this study. An inversion was present in some individuals for $p s b A-\operatorname{trn} H$, and this was inverted to match the sequences of the majority of samples prior to analyses.

\section{Phylogenetic Analysis}

All three methods of analysis resulted in trees that were nearly identical and fully compatible with each other for the concatenated data from the seven regions. The greatest resolution was in the Bayesian inference (BI) trees and the lowest in the MP trees. Maximum parsimony resulted in 138 trees, length $=1585$, consistency index $(\mathrm{CI})=0.5408$, retention index $(\mathrm{RI})=0.8518$, and rescaled consistency index $(\mathrm{RC})=0.5283$. Analyses of cpDNA and nrDNA separately did not result in any conflicting relationships between the two analyses. The model GTR $+\mathrm{G}$ was selected by jmodeltest, and this model was implemented in the $\mathrm{BI}$ analyses. Results from the two independent runs were in full agreement in terms of topology and differed by only one or two posterior probability points. Topologies and support did not differ regardless of whether the Beagle library was included. The ESS values were 3188 and 2684, respectively, for the two runs. The BI tree is presented in figure 2 with MPBS, MLBS, and BIPP values shown for all nodes. Clades for species with multiple sampled individuals are collapsed. Figure S1 (available online) has all samples. Support for relationships along the backbone of the tree remains low, but the monophyly of all species (except Columnea sanguinea; see "Discussion") that included more than a single individual is strongly to maximally supported, and several clades receive strong to maximal support from at least one analysis (figs. 2, S1).

A monophyletic (but not supported) section Angustiflorae and a monophyletic (supported in all analyses) section Columnea were recovered. All Jamaican species were recovered as monophyletic with maximal support from all analyses with Columnea tincta from Cuba sister to the Jamaican species except for Columnea pubescens that is sister to C. tincta + 12 Jamaican species (fig. 2). A clade comprising Columnea rubricalyx, Columnea dissimilis, Columnea pulchra, Columnea fimbricalyx, Columnea herthae, and Columnea minutiflora is sister to the JCE species, but this relationship is not supported (fig. 2). Caribbean species of Columnea were not recovered as monophyletic with Columnea scandens in section Columnea; Columnea ambigua and Columnea domingensis sister to each other in section Angustiflorae; and two accessions of C. sanguinea from Hispaniola and Cuba sister to each other but not monophyletic with one other accession of C. sanguinea from a cultivated collection with unknown natural provenance (fig. 2; appendix).

\section{Testing Alternative Topologies}

The AU tests could not reject the sister group relationship of the JCE clade to section Columnea $(P=0.359)$. However, all other relationships of JCE to section Columnea were rejected, including the JCE clade in section Columnea as a fourth clade in the polytomy (fig. $2 ; P=0.031$ ) or as sister to any of the clades within section Columnea (fig. $2 ; P<0.001$ ). The AU tests also rejected the monophyly of all endemic Caribbean species of Columnea ( $P=0.05$ if C. ambigua and C. domingensis are sister to the unconstrained topology of the JCE clade, $P<0.001$ if the JCE clade is sister to the unconstrained placement of $C$. ambigua and $C$. domingensis), the monophyly of all Caribbean species of Columnea $(P<0.0001)$, and the monophyly of $C$. sanguinea whether the two Caribbean species were placed with the unconstrained placement of the cultivated individual $(P<$ $0.001)$ or with the cultivated individual placed with the unconstrained placement of the Caribbean individuals $(P<0.001)$. A monophyletic Columnea hirsuta s. l. such that C. hirsuta, Columnea fawcettii, Columnea harrisii, Columnea proctorii, and Columnea urbanii was monophyletic was also rejected $(P<$ 0.001).

\section{Discussion}

\section{Caribbean Biogeography}

Columnea fits a general pattern in Caribbean biogeography with multiple independent introductions into the islands and with populations of species found on the islands that exist in mainland populations as well (Seutin et al. 1994; Negrón-Ortiz and Watson 2003; Fritsch 2003; Joseph et al. 2004; SantiagoValentin and Olmstead 2004; Roncal et al. 2008; Van Ee and Berry 2009; Rodríguez et al. 2010). Our data indicate a minimum of four independent introductions into the Caribbean: (1) Columnea ambigua and Columnea domingensis, (2) Columnea 


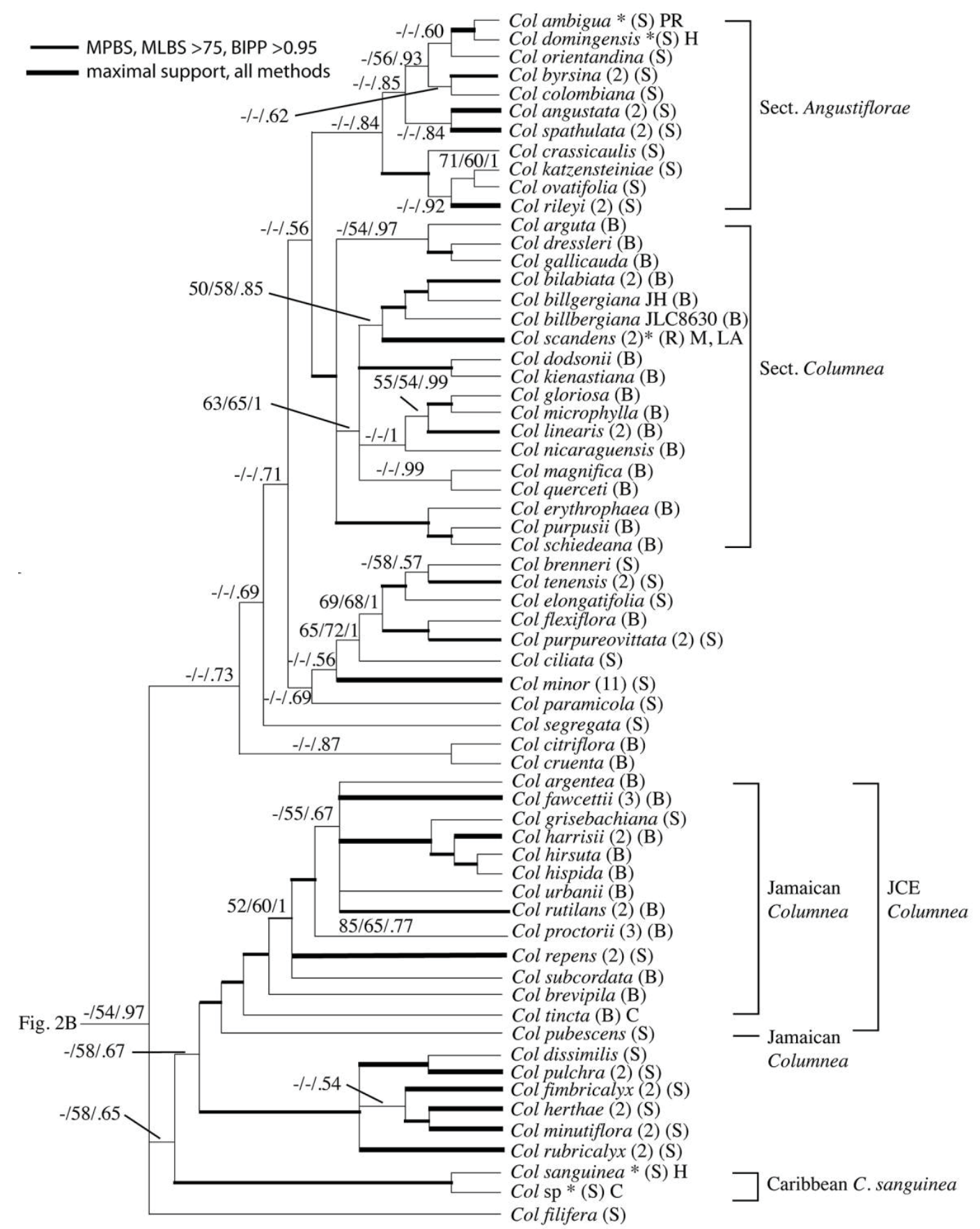

Fig. 2 Majority-rule consensus tree derived from Bayesian inference. Values on branches are maximum parsimony bootstrap/maximum likelihood bootstrap/Bayesian posterior probabilities. Branches supported in all three analyses are those with thick black lines. Letters in parentheses after names indicate corolla morphology as subradial (S), bilateral (B), or hypocyrtoid (H), a morphology with a narrow opening and strongly ventricose corolla tube. Caribbean and Jamaican species are marked with brackets to the right of the tree, as are sections Angustiflorae and Columnea, which are discussed in the text. JCE refers to the Jamaican/Cuban endemic species. Other species with Caribbean distributions are marked with asterisks. Specific islands are indicated other than the Jamaican species to indicate Cuba (C), Hispaniola (H), Lesser Antilles (LA), mainland (M), and Puerto Rico (R). 


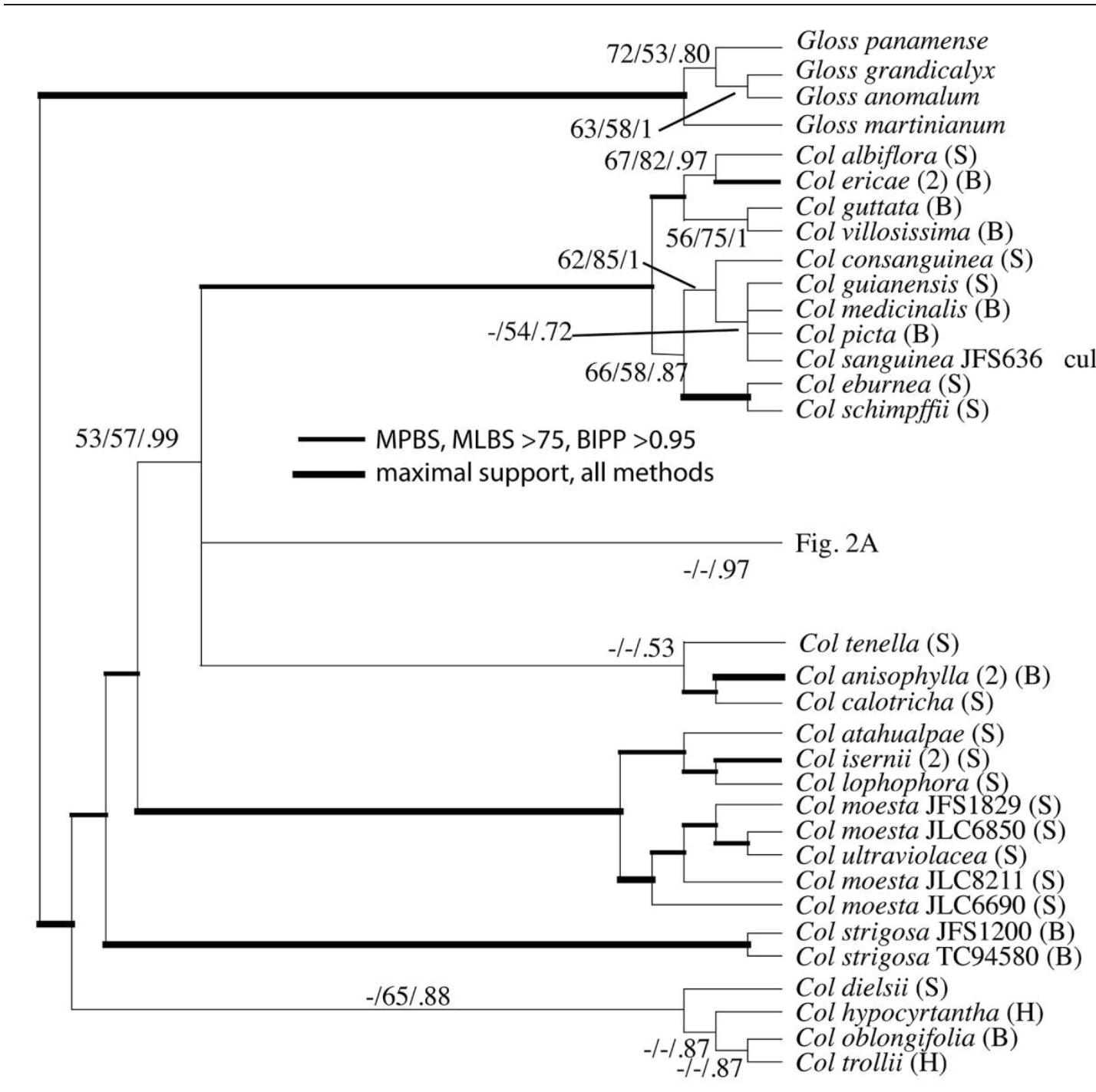

Fig. 2 (Continued)

sanguinea, (3) Columnea scandens, and (4) the JCE species (fig. 2).

The inclusion of C. sanguinea from Hispaniola and an unvouchered specimen from Cuba implies that the Cuban collection is also C. sanguinea, and it is likely that a single introduction into the Caribbean occurred for this species. However, the lack of a voucher for the one specimen creates uncertainty surrounding this determination, as well as the fact that these two are not monophyletic with one other collection of C. sanguinea derived from cultivated material presumably with a mainland provenance (fig. 2). These results imply that the Caribbean $C$. sanguinea may be evolutionarily distinct from those of the mainland populations, but we also cannot preclude that the cultivated accession of C. sanguinea may have resulted from interspecific crosses with other cultivated species. Further sampling will be essential to verify this. Two samples of C. scandens are recovered as sister to each other, one from the island of Martinique, the other from cultivation, again presumably from a mainland source. Although C. scandens is clearly monophyletic, the sampling of this species from only one Caribbean island cannot preclude that independent multiple introductions have occurred. Further sampling and analyses at the population level would be essential to resolve this.

Our current data do not allow us to fully test the source populations of the introductions of the endemic species due to poor support on those parts of the tree. Both C. ambigua and C. domingensis are sister to each other and together are within section Angustiflorae (fig. 2; Schulte et al. 2014, 2015). Nearly all members of section Angustiflorae are from South America, with a few individuals of Columnea angustata recorded from Central America. Therefore, it is almost a certainty that the ancestor to these two species would have been from mainland 
South America, with an introduction to either Puerto Rico where C. ambigua is endemic or Hispaniola where C. domingensis is endemic, with a subsequent migration from one to the other adjacent island.

The origin of the JCE clade is more complicated than C. ambigua/C. domingensis in that the JCE clade is recovered in all analyses as sister to a clade including Columnea dissimilis (fig. 2) but is not supported. If the topology is correct, the species in the C. dissimilis clade are known primarily from Colombia and Ecuador; therefore, a South American origin for JCE would be likely. However, as AU tests cannot preclude the sister group relationship to section Columnea, and the shared corolla morphologies between these two clades argues for common ancestry, we cannot eliminate a Central American ancestor for the JCE clade.

\section{Monophyly of Jamaican Species and Relationships within the Clade}

The data provide strong support for a single ancestral introduction into Jamaica for Columnea (fig. 2). Single ancestral introductions in Jamaica are known for several other taxa and include Anolis (lizards; Hedges and Burrell 1990), Selenops (spiders; Crews and Gillespie 2010), land crabs (Schubart et al. 1998), Limia (fish; Weaver et al. 2016), and the plant genus Erithallis (Negrón-Ortiz and Watson 2003). However, many other studies have demonstrated multiple introductions into the island, often because of a single or few widespread species also found on other islands or the mainland and which include the plant genera Rochefortia (Irimia et al. 2015) and Croton (Van Ee and Berry 2009) as well as Myarchus flycatchers (Joseph et al. 2004).

Relationships within the clade are not all strongly supported, but many of them are. First, in all instances where multiple individuals were sampled, all species are recovered as monophyletic (fig. 2). Previous taxonomic treatments had considered C. fawcettii, Columnea harrisii, C. proctorii, and C. urbanii all to be members of a more broadly circumscribed C. hirsuta (Urban 1901). This broader concept of C. hirsuta was not recovered as a monophyletic group that would exclude species not previously considered to be conspecific, and a constrained broader concept of C. hirsuta could be rejected with AU tests. This provides additional reassurance that the 13 species on Jamaica are evolutionarily distinct and that the greater number of species on the island do not represent simply a taxonomic anomaly.

Stearn (1968) used the Jamaican species of Columnea to demonstrate phenetic relationships of the species using 51 cytological, biochemical, anatomical, and macroscopic morphological characters in a phenetic analysis. The resulting dendrogram also included several hybrid individuals, but ignoring these, Stearn (1968) recovered a clade of Columnea rutilans, C. hirsuta, and C. fawcettii in a polytomy; another polytomy of C. proctorii, Columnea subcordata, and C. urbanii; and a third clade of C. harrisii sister to the sister pair of Columnea brevipila and Columnea argentea. These three clades were monophyletic in a polytomy. He also recovered Columnea grisebachiana, Columnea pubescens, and C. ambigua (all then treated as species of $\mathrm{Al}$ loplectus) as a polytomy with Columnea hispida as sister. Finally, all three clades were in a polytomy with Columnea repens (called Columnea jamaicensis). Despite this study using a fairly large number of characters and being one of the earliest to use any form of phylogenetic analysis in Gesneriaceae, the resulting phenetic topology is in complete disagreement with the results of the molecular analyses presented here.

\section{Classification of the JCE Clade}

Although no single analysis recovered the Jamaican clade as a part or sister to section Columnea, the AU tests cannot exclude the possibility that they may be sister to section Columnea but do exclude the inclusion of the JCE clade within section Columnea (fig. 2). The corolla of Columnea tincta is nearly identical to that of C. urbanii or C. proctorii (fig. $1 H$; Morley 1974), and its sister relationship to the Jamaican species except C. pubescens implies an ancestral origin for this corolla form. A possible explanation is that an ancestor dispersed to Jamaica with subsequent dispersal to Cuba as likely occurred with C. ambigua/C. domingensis. Although 10 of the 13 species on Jamaica share a corolla morphology with section Columnea and have been traditionally considered members of this clade (Morley 1974, 1976; Wiehler 1983), the inclusion of the remaining three species would alter the characters defining section Columnea because the radial to subradial corollas of C. grisebachiana, C. pubescens, and C. repens would not share the feature that defines section Columnea: a bilabiate corolla with a galea and long nonventricose corolla tube (Morley 1976; Wiehler 1983). Therefore, we do not propose including members of the JCE within section Columnea, and a new section will be essential to encompass these species.

\section{Higher Diversity in Jamaica Compared with Other Islands}

A recent analysis of diversification rates and the potential processes that drive those rates across the entire Gesneriaceae (Roalson and Roberts 2016) demonstrated that floral form and color in New World Gesneriaceae are important factors in increased rates of diversification. Roalson and Roberts (2016) found mixed results that epiphytism could increase rates of diversification. Our present study focuses on part of a single genus within the family, but Columnea species are mostly assumed to be hummingbird pollinated and most species are epiphytic (Wiehler 1983). Roalson and Roberts (2016) demonstrated that tribe Columneineae (Alloplectus, Columnea, Drymonia, Glossoloma, and Neomortonia) had the fourth-highest diversification and fifth-highest speciation rate among the eight groups compared. The scale of their study compared with the present one makes generalizations between the two difficult, and here we attempt to explain the higher rate of diversification found on Jamaica in comparison to other Caribbean islands.

The greater number of species of Columnea found in the Caribbean compared with other nonendemic genera of Gesneriaceae is the result of the 13 endemic species on Jamaica. The high number of species on this island is somewhat puzzling, especially since other taxonomic groups have reduced diversity on Jamaica compared with diversity on other islands (Lavin and Matos 2008; Acevedo-Rodriguez and Strong 2017). The puzzle is why there is such a large number of Columnea species on Jamaica. Knowing that the Jamaican species represent a single introduction to the island, factors relating to propagule pressure to ex- 
plain higher diversity (such as proximity to mainland areas) are not valid explanations. Island biogeography theory predicts that larger islands are expected to harbor more species. Jamaica is the third-largest island in the Caribbean, and yet only two species of Columnea are known from Cuba and Hispaniola: C. sanguinea found on both islands and the mainland, and one endemic species on each island. Additionally, Jamaica was either nearly completely or completely submerged at the time GAARlandia provided a connection to South America (IturaldeVinent and MacPhee 1999), although both Cuba and Hispaniola would have been part of this connection.

The age of islands may provide an explanation, with older islands having longer times for speciation and divergence to occur. Although the block that Jamaica occupies likely collided with the Guatemala-Yucatan platform in the Paleocene, the island was likely completely submerged in the middle to late Eocene and remained submerged until the late Miocene (Buskirk 1985; Ituralde-Vinent and MacPhee 1999; Graham 2003). Thus, although there may have been a chance for biotic exchange with Central America in the Paleocene, any endemic biota would have been eliminated in the Miocene and all endemic taxa would have to have evolved within a 25-5 myr time frame. In contrast, Cuba and Hispaniola had portions of both islands emergent consistently during that time period (Buskirk 1985; Ituralde-Vinent and MacPhee 1999; Graham 2003). Thus, it appears that the geological history of Jamaica does not help to explain the higher number of endemic species of Columnea found there compared with other Caribbean islands.

Topography can also affect rates of species diversification (Richerson and Lum 1980; Kruckeberg 1986; Steinbauer et al. 2016), especially if elevation gradients generate distinct and isolated climates or populations. Although most species of $\mathrm{Col}$ umnea that have been investigated have similar climatic requirements (Schulte et al. 2015), isolated populations could lead to diversification and speciation (Schulte et al. 2015). Jamaican species have some overlap in their distributions but are largely allopatric (Morley 1972). Jamaica is certainly more mountainous than Cuba, with the highest elevation at Blue Mt. Peak $(2256 \mathrm{~m})$ and several other elevations above $2100 \mathrm{~m}$. The geology of the island also varies with the Central mountains' igneous origins and metamorphic rock with karst limestone hills in the Cockpit country (Arden 1975). In contrast, Cuba has less topographic diversity with the Sierra Maestra and the highest peak of Pico Turquino (1974 m). The combination of flat to rolling hills and large swaths of serpentine soils in Cuba (Borhidi 1991) has created large barriers (Berazaín Iturralde 2001) and isolated areas where Columnea would typically diversify. The mountains and lack of serpentine soils in Jamaica are more similar to Andean forests in South America and therefore more conducive for the diversification of Columnea. Although the more varied topography of Jamaica compared with Cuba may be an explanation for the greater diversity of Columnea in Jamaica, it does not suffice to explain that diversity in comparison to Hispaniola. Hispaniola has five major mountain ranges: Cordillera Central, Cordillera Septentrional, Massif du Nor, Sierra de Bahoruco, and Sierra de Neiba. Two of these ranges have peaks higher than any found in Jamaica (Pico Duarte $=3175 \mathrm{~m}$, and Pic la Selle $=$ $1680 \mathrm{~m}$; Latta et al. 2010). Thus, if topographic variation were a single explanation for diversification in Caribbean Columnea, one would expect greater diversification on Hispaniola.
The bilaterally symmetric flaring corolla (fig. 1) found in 10 of the 13 endemic species of Columnea on Jamaica could also be a key innovation for this group, allowing greater diversification (Givnish and Sytsma 2000). A shift from marine to terrestrial habitat has been the major explanation for a rapid radiation of crabs in Jamaica (Schubart et al. 1998). It is possible that a similar key innovation in Columnea may be the corolla. It is not clear, at present, how this may have acted as a key innovation. Presumably, the larger opening allows for a greater number of hummingbird visitors, but it is unclear how this may have promoted greater diversity. Additionally, because we cannot reject the sister group relationship between the Jamaican species and section Columnea (the second-largest section in the genus in terms of number of species), it is possible that the Jamaican species inherited this trait from a common ancestor with shifts to a subradial corolla occurring in three of the species. However, similar corollas are found in C. scandens of section Columnea, and there has not been substantial diversification in this lineage in the Caribbean. Even more compelling against the argument that the corolla is a key innovation is the sister relationship of C. tincta to 12 of the Jamaican endemic species. Columnea tincta shares a corolla morphology (fig. $1 H$ ) with most of the endemic Jamaican species, and as sister to all but C. pubescens, the lineages are the same age. However, the Jamaican lineage diverged into 12 species, whereas C. tincta is the only endemic species of Columnea on Cuba.

A final possible explanation may be genetic isolation if there were a greater number of pollinators or dispersers on Jamaica that might generate reproductive barriers between species. Litthe is known about dispersal or pollination in Columnea in general (Morley 1971, 1974; Schulte et al. 2015) and even less about the Jamaican species, although the data that do exist point to hummingbirds as primary pollinators (Morley 1971, 1974), and the flowers clearly fit a hummingbird pollination syndrome (Proctor et al. 1996). Jamaica is home to four different species of hummingbird (three if the red-billed and blackbilled streamertails are considered subspecies; Downer and Sutton 1990). Three of these are endemic to the island, and the Vervain hummingbird on Jamaica is considered an endemic subspecies. Although this is a larger number of hummingbirds on Jamaica in comparison to Hispaniola (three species; Latta et al. 2010) and Cuba (two species; Garrido and Kirkconnell 2000), it seems unlikely that the one to two additional species on Jamaica are sufficient to drive speciation to this level. Speciation by isolation by hummingbirds is even less likely when we consider that the Jamaican species were some of the first documented cases of natural interspecific hybridization in the genus (Morley 1971, 1976). Thus, it seems unlikely that four species of birds would have effectively driven isolation to bring about 13 endemic species of plants.

Even less is known about dispersal in Columnea. Blake and Loiselle (1992) documented seeds of Besleria columneoides Hanst. and Drymonia pilifera Wiehler in feces of migratory thrushes. Columnea species have fleshy fruits similar to those of Besleria and Drymonia; therefore, it is likely that these birds would be likely consumers of Columnea fruits as well. There are 10 species of thrush on Jamaica, 11 on Cuba, and nine on Hispaniola. Therefore, again it seems unlikely that if thrushes are primary dispersers of Columnea fruits, the numbers on Jamaica would have an impact. 
Another unusual trait regarding the Jamaican species of Columnea is the degree of sequence divergence that is (1) shared among all species such that the clade is maximally supported as monophyletic in all analyses, a result not seen in other clades that presumably have had a longer time to diverge in comparison to the limited age of an emergent Jamaica, and (2) the sequence divergence found within the clade. Although not all relationships are well supported, there are four clades among 12 species (excluding C. pubescens and C. tincta) that have strong to maximal support in all analyses, and the sister relationship of C. hirsuta to C. hispida is strongly supported with MLBS (89) and BIPP (1.0) but is just short of being supported with MPBS (72). In comparison, with 17 out of ca. 75 species of section Columnea sampled, there are seven interspecific nodes with support and only two nodes supported in section Angustiflorae (fig. 2). This larger number of nonhomoplastic phylogenetically informative characters for the Jamaican species, despite the short geological time frame for divergence on Jamaica, im- plies rapid divergence with what would likely have been small populations such that mutations would become fixed for the lineages in a short time period (Bush et al. 1977; Slatkin 1987; Charlesworth and Charlesworth 1997).

\section{Acknowledgments}

We thank the anonymous reviewers for their contributions to the manuscript, the editorial board of the International Journal of Plant Sciences, and the staff of the National Environmental and Planning Agency of Jamaica for assistance in obtaining permits to collect material there. A Research and Exploration Grant from the National Geographic Society to J. L. Clark (9522-14) supported fieldwork in Cuba. Funding was made available through National Science Foundation grant DEB0949270 to J. F. Smith and J. L. Clark.

\section{Appendix}

Species, voucher specimens, and GenBank accession numbers for all accessions included in phylogenetic analyses. Data are in the order, taxon, voucher, herbarium, collection locality, and GenBank accession numbers for: $r p l 32-t_{r n L} L_{U A G}$ spacer, trnQ-rps16 intron, $r p s 16$ intron, $t r n S-G$ spacer, $t r n H-p s b A$ spacer, ITS, and ETS. Numbers in bold are new for this study, NA $=$ not available.

Ingroup: C. albiflora L. P. Kvist \& L. E. Skog, J. L. Clark \& J. Rea 8015, UNA, Ecuador, KF005812, KF006030, KF005921, JQ953700, DQ211219, DQ211111, MK326129. C. ambigua (Urb.) B. D. Morley, J. Smith 3701, SRP, cultivated originally Puerto Rico, KF005814, KF006032, KF005923, JQ953713, KF005641, JQ953789, MK326130. C. angustata (Wiehler) L. E. Skog, J. F. Smith 1433, WIS, Colombia, KF005815, KF006033, KF005924, KF006136, KF005642, KF005726, MK326131. C. angustata (Wiehler) L. E. Skog, J. L. Clark 8627, UNA, Panama, KF005816, KF006034, KF005925, KF006137, NA, KF005727, MK326132. C. anisophylla DC., J. L. Clark \& J. Rea 8019, UNA, Ecuador, KF005819, KF006037, KF005926, KF006141, KF005646, KF005728, MK326134. C. anisophylla DC., E. Tepe 1081, SRP, Panama, KF005817, KF006035, KF005927, KF006138, KF005643, KF005729, MK326133. C. argentea Griseb., J. F. Smith et al. 10047, SRP, Jamaica, MK326237, MK326352, MK326086, MK326313, MK326276, MK326047, MK326135. C. arguta C. V. Morton, J. Harrison \& L. Harrison 685, SRP, Panama, MK326238, MK326353, MK326087, MK326314, NA, MK326048, MK326136.

C. atahualpae J. F. Smith \& L. E. Skog, J. L. Clark et al. 8000, UNA, Ecuador, KF005821, KF006038, KF005930, KF006142, KF005647, KF005732, MK326137. C. bilabiata Seem., J. L. Clark et al. 11157, UNA, Ecuador, KF005822, KF006039, KF005931, KF006143, KF005648, KF005733, MK326139. C. bilabiata Seem., J. F. Smith et al. 10896, COL, Colombia, MK326239, MK326354, MK326088, MK326315, MK326277, MK326049, MK326138. C. billbergiana Beurl., J. L. Clark 8630, US, Panama, MK326240, MK326355, MK326089, MK326316, MK326278, MK326050, MK326140. C. billbergiana Beurl., J. Harrison \& L. Harrison 683, SRP, Panama, MK326241, MK326356, MK326090, MK326317, NA, MK326051, MK326141. C. brenneri (Wiehler) B. D. Morley, J. F. Smith 3385, SRP, Ecuador, KF005823, KF006040, KF005932, KF006144, KF005649, KF005734, MK326142. C. brevipila Urb., J. F. Smith 10058, SRP, Cultivated, originally from Jamaica, KF005825, KF006042, KF005934, KF006146, KF005651, KF005736, MK326143.

C. byrsina (Wiehler) L. P. Kvist \& L. E. Skog, J. F. Smith 3408, SRP, Ecuador, KF005826, KF006043, KF005935, JQ953714, KF005652, KF005737, MK326144. C. byrsina (Wiehler) L. P. Kvist \& L. E. Skog, J. L. Clark \& O. Meija 6291, UNA, Ecuador, KF005827, KF006044, KF005936, KF006148, KF005653, KF005738, MK326145. C. calotricha Donn. Sm., J. F. Smith et al. 4117, SRP, French Guiana, KF005828, KF006045, KF005937, KF006149, KF005654, KF005739, MK326146. C. ciliata (Wiehler) L. P. Kvist \& L. E. Skog, J. L. Clark et al. 7508, UNA, Ecuador, KF005829, KF006046, KF005938, KF006150, MK326279, KF005740, MK326147. C. citriflora L. E. Skog, J. L. Clark 10053, UNA, cultivate, originally from Panama, KF005830, KF006047, KF005939, KF006151, KF005655, KF005741, MK326148. C. colombiana (Wiehler) L. P. Kvist \& L. E. Skog, J. F. Smith 1126, WIS, cultivated at SEL, KF005832, KF006049, KF005941, KF006153, KF005657, KF005743, MK326149. C. consanguinea Hanst., E. Tepe 1082, SRP, Panama, KF005833, KF006050, KF005942, KF006154, KF005658, KF005744, MK326150. C. crassicaulis (Wiehler) L. P. Kvist \& L. E. Skog, J. L. Clark 8859, US, cultivated, KF005834, KF006051, KF005943, KF006155, KF005659, KF005745, MK326151. C. cruenta B. D. Morley, J. F. Smith 8606, SRP, Cultivated, KF005835, KF006052, KF005955, KF006156, KF005660, KF005746, MK326152. C. dielsii Mansf., J. F. Smith 1989, WIS, Ecuador, KF005836, KF006053, KF005945, KF006157, KF005661, KF005747, NA. C. dissimilis C. V. Morton, E. Tepe 1070, SRP, Panama, KF005837, KF006054, KF005946, KF006158, KF005662, KF005748, MK326153. C. dodsonii Wiehler, B. Stewart s. n., SRP, Cultivated, KF005838, KF006055, KF005947, KF006159, KF005663, KF005749, MK326154. C. domingensis (Urb.) B. D. Morley, L. Hahn 445, SRP, Dominican Republic, KF005839, KF006056, KF005948, JQ953715, KF005664, JQ953790, 
MK326155. C. dressleri Wiehler, J. L. Clark \& L. Espinosa 8559, US, Panama, MK326242, MK326357, MK326091, MK326318, MK326280, MK326052, MK326156. C. eburnea (Wiehler) L. P. Kvist \& L. E. Skog, J. L. Clark et al. 6353, US, Ecuador, KF005840, KF006057, KF005949, KF006160, KF005665, KF005750, MK326157. C. elongatifolia L. P. Kvist \& L. E. Skog, J. L. Clark et al. 10015, US, Cultivated, originally from Ecuador, KF005841, KF006058, KF005950, KF006161, KF005666, KF005751, MK326158. C. ericae Mansf., J. L. Clark et al. 6920, UNA, Ecuador, KF005842, KF006059, KF005951, KF006162, KF005667, KF005752, MK326160. C. ericae Mansf., E. Tepe 1570, SRP, Ecuador, KF005818, NA, KF005928, KF006139, KF005644, KF005730, MK326159. C. erythrophaea Decne. ex Houllet, J. F. Smith 3727, SRP, Cultivated, KF005843, KF006060, KF005952, KF006163, KF005668, AF543246, MK326161. C. fawcettii (Urb.) C. V. Morton, J. F. Smith et al. 10040, SRP, Jamaica, MK326243, MK326358, MK326092, MK326319, MK326281, MK326053, MK326162. C. fawcettii (Urb.) C. V. Morton, J. F. Smith et al. 10042, SRP, Jamaica, MK326244, MK326359, MK326093, MK326320, MK326282, MK326054, MK326163. C. fawcettii (Urb.) C. V. Morton, J. F. Smith et al. 10044, SRP, Jamaica, MK326245, MK326360, MK326094, MK326321, MK326283, MK326055, MK326164. C. filifera (Wiehler) L. P. Kvist \& L. E. Skog, J. L. Clark et al. 7140, UNA, Ecuador, KF005844, KF006061, KF005954, KF006165, KF005669, KF005753, MK326165. C. fimbricalyx L. P.. Kvist \& L. E. Skog, J. L. Clark et al. 7395, UNA, Ecuador, KF005845, KF006062, KF005955, KF006166, KF005670, KF005754, MK326167. C. fimbricalyx L. P. Kvist \& L. E. Skog, J. L. Clark et al. 10429, UNA, Ecuador, MK326246, MK326361, MK326095, MK326322, MK326284, MK326056, MK326166. C. flexiflora L. P. Kvist \& L. E. Skog, J. L. Clark o. L. Jost 6968, UNA, Ecuador, KF005846, KF006063, KF005956, KF006167, KF005671, KF005755, MK326168. C. gallicauda Wiehler, J. L. Clark 6283, UNA, cultivated, KF005847, KF006064, KF005957, KF006168, KF005672, KF005756, MK326169. C. gloriosa Spraque, J. L. Clark et al. 9921, UNA, Ecuador, KF005848, KF006065, KF005958, KF006169, KF005673, KF005757, MK326170. C. grisebachiana Kuntze, J. F. Smith et al. 10041, SRP, Jamaica, MK326247, MK326362, MK326096, MK326323, MK326285, MK326057, MK326171. C. guianensis C. V. Morton, J. F. Smith 3711, SRP, Guyana, KF005849, KF006066, KF005959, JQ953718, KF005674, JQ953791, MK326172. C. guttata Poepp., J. L. Clark \& L. Jost 6974, UNA, Ecuador, KF005850, KF006067, KF005960, KF006170, KF005675, KF005759, MK326173. C. harrisii (Urb.) Britton ex C. V. Morton, J. L. Clark 6278, US, Cultivated, originally from Jamaica, MK326249, MK326364, MK326098, MK326325, MK326287, MK326059, MK326175. C. harrisii (Urb.) Britton ex C. V. Morton, J. F. Smith et al. 10055, SRP, Jamaica, MK326248, MK326363, MK326097, MK326324, MK326286, MK326058, MK326174. C. herthae Mansf., J. L. Clark et al. 4960, UNA, Ecuador, KF005852, KF006070, KF005961, KF006172, KF005676, KF005760, MK326176. C. herthae Mansf., J. L. Clark et al. 7113, UNA, Ecuador, KF005853, KF006069, KF005963, KF006173, KF005677, KF005761, MK326177. C. hirsuta Sw., J. F. Smith et al. 10057, SRP, Jamaica, MK326250, MK326365, MK326099, MK326326, MK326288, MK326060, MK326178. C. hispida Sw., J. F. Smith et al. 10054, SRP, Jamaica, MK326251, MK326366, MK326100, MK326327, MK326289, MK326061, MK326179. C. hypocyrtantha (Wiehler) J. F. Smith \& L. E. Skog, J. L. Clark \& E. Rodriguez 6741, US, Bolivia, KF005854, KF006071, KF005964, KF006174, KF005679, KF005762, MK326180. C. isernii Cuatr., J. L. Clark et al. 6253, UNA, Ecuador, KF005857, KF006074, KF005967, KF006177, DQ211220, AF543247, MK326182. C. isernii Cuatr., J. F. Smith 2010, WIS, Ecuador, KF005856, KF006073, KF005966, KF006176, KF005681, KF0057645, MK326181. C. katzensteiniae (Wiehler) L. P. Kvist \& L. E. Skog, J. L. Clark et al. 7625, UNA, Ecuador, KF005858, KF006075, KF005968, KF006178, KF005683, KF005766, MK326183. C. kienastiana Regel, J. F. Smith et al. 10931, COL, Colombia, MK326252, MK326367, MK326101, MK326328, MK326290, MK326062, MK326184. C. linearis Oerst., J. L. Clark 6274, US, Cultivated, originally from Costa Rica, MK326254, MK326369, MK326103, MK326330, MK326292, MK326064, NA. C. linearis Oerst., no voucher, NA, Cultivated, MK326253, MK326368, MK326102, MK326329, MK326291, MK326063, NA. C. lophophora Mansf. , J. L. Clark et al. 7888, US, Ecuador, KF005860, KF006076, KF005969, KF006179, KF005684, KF005767, MK326185. C. magnifica Klotzsch ex Oerst., J. F. Smith 8602, SRP, Cultivated, KF005861, KF006078, KF005971, KF006181, KF005685, KF005769, MK326186. C. medicinalis (Wiehler) L. E. Skog \& L. P. Kvist, J. F. Smith 1972, WIS, Ecuador, KF005862, KF006079, KF005972, KF006164, KF005686, KF005770, MK326187. C. microphylla Klotsch \& Hanst., J. L. Clark 6261, UNA, cultivated, KF005863, KF006080, KF005973, KF006182, KF005687, KF005771, MK326188. C. minor (Hook.) Hanst., J. L. Clark 2934, SRP, Ecuador, KF005864, KF006081, MK326107, KF006183, KF005688, KF005772, NA. C. minor (Hook.) Hanst., J. L. Clark et al. 6220, US, Ecuador, MK326258, MK326373, MK326108, MK326334, MK326296, MK326068, NA. C. minor (Hook.) Hanst., J. L. Clark \& O. Mejia 6289, US, Ecuador, MK326259, MK326374, MK326109, MK326335, MK326297, MK326069, NA. C. minor (Hook.) Hanst., J. L. Clark \& E. Folleco 8504, US, Ecuador, MK326260, MK326375, MK326110, MK326336, MK326298, MK326070, NA. C. minor (Hook.) Hanst., J. L. Clark et al. 9647, UNA, Ecuador, MK326261, MK326376, MK326111, MK326337, MK326299, MK326071, NA. C. minor (Hook.) Hanst., T. Croat 94778, MO, Ecuador, KF005866, KF006084, KF005975, KF006185, KF005690, KF005774, NA. C. minor (Hook.) Hanst., O. H. Marín-Gómez 260, COL, Colombia, MK326262, MK326377, MK326112, MK326338, MK326300, MK326072, NA. C. minor (Hook.) Hanst., J. F. Smith et al. 10839, COL, Colombia, MK326255, MK326370, MK326104, MK326331, MK326293, MK326065, NA. C. minor (Hook.) Hanst., J. F. Smith et al. 10872, COL, Colombia, MK326256, MK326371, MK326105, MK326332, MK326294, MK326066, NA. C. minor (Hook.) Hanst., J. F. Smith et al. 10932, COL, Colombia, MK326257, MK326372, MK326106, MK326333, MK326295, MK326067, NA. C. minor (Hook.) Hanst., B. Stewart s. n., SRP, Cultivated, KF005865, KF006082, KF005974, KF006184, KF005689, KF005773, NA. C. minutiflora L. P. Kvist \& L. E. Skog, J. L. Clark et al. 7092, US, Ecuador, KF005868, KF006086, KF005977, KF006187, KF005692, KF005776, MK326190. C. minutiflora L. P. Kvist \& L. E. Skog, J. L. Clark et al. 10832, UNA, Ecuador, KF005867, KF006085, KF005976, KF006186, KF005691, KF005775, MK326189. C. moesta Poepp., J. F. Smith 1829, WIS, Bolivia, KF005870, KF006084, KF005979, KF006189, KF005694, KF005778, MK326191. C. moesta Poepp., 
J. L. Clark \& M. Zeballos 6850, UNA, Bolivia, KF005872, KF006089, KF005981, KF006191, KF005695, KF005779, MK326193. C. moesta Poepp., J. L. Clark \& D. Barrientos 6690, US, Bolivia, KF005871, KF006088, KF005980, KF006190, DQ211242, DQ211123, MK326192. C. moesta Poepp., J. L. Clark et al. 8211, UNA, Peru, KF005873, KF006091, KF005982, KF006192, KF005696, KF005780, MK326194. C. nicaraguensis, J. L. Clark et al. 10023, US, Cultivated, MK326263, MK326378, MK326113, MK326339, MK326301, MK326073, NA. C. oblongifolia Rusby, J. F. Smith 1721, WIS, Bolivia, KF005874, KF006092, KF005983, KF006193, KF005697, KF005781, MK326195. C. orientandina Mansf., J. L. Clark et al. 9885, UNA, Ecuador, KF005876, KF006094, KF005985, KF006195, KF005699, KF005783, MK326196. C. ovatifolia L. P. Kvist \& L. E. Skog, J. F. Smith 1921, WIS, Ecuador, KF005877, KF006091, KF005986, KF006196, KF005700, KF005784, MK326197. C. paramicola (Wiehler) L. P. Kvist \& L. E. Skog, no voucher USBRG94529, NA, Cultivated, KF005878, KF006095, KF005987, JQ954064, DQ211224, DQ211113, MK326198. C. picta H. Karst., T. Croat 94956, MO, Ecuador, KF005879, KF006096, KF005988, KF006197, KF005701, KF005785, MK326199. C. proctorii Stearn, J. F. Smith et al. 10048, SRP, Jamaica, MK326264, MK326379, MK326114, MK326340, MK326302, MK326074, MK326200. C. proctorii Stearn, J. F. Smith et al. 10052, SRP, Jamaica, MK326265, MK326380, MK326115, MK326341, MK326303, MK326075, MK326201. C. pubescens (Griseb.) Kuntze, K. Campbell et al. 17.05.18, IJ, Jamaica, MK326266, MK326381, NA, MK326342, NA, MK326077, MK326203. C. pulchra (Wiehler) L. E. Skog, J. L. Clark 6265, US, cultivated, KF005880, MK326382, KF005990, KF006198, DQ211225, KF005786, MK326205. C. pulchra (Wiehler) L. E. Skog, no voucher, NA, Cultivated, KF005881, KF006097, KF005989, KF006199, KF005702, KF005787, MK326204. C. purpureovittata (Wiehler) B. D. Morley, J. L. Clark et al. 11448, UNA, Peru, KF005882, KF006098, KF005991, KF006200, KF005703, KF005788, MK326207. C. purpureovittata (Wiehler) B. D. Morley, J. F. Smith s. n., SRP, Cultivated, KF005855, KF006072, KF005965, KF006175, KF005680, KF005763, MK326206. C. purpusii Standl., A. Rincon et al. 2302, XAL, Mexico, KF005883, KF006099, KF005992, JQ953719, KF005704, JQ953792, MK326208. C. querceti Oerst., J. L. Clark 10047, US, Cultivated, originally from Costa Rica, MK326267, MK326383, MK326116, MK326343, MK326304, MK326078, MK326209. C. repens (Hook.) Hanst., J. F. Smith 8605, SRP, Cultivated, originally from Jamaica, KF005884, KF006100, KF005993, KF006201, KF005705, KF005790, MK326211. C. repens (Hook.) Hanst., J. F. Smith et al. 10056, SRP, Jamaica, MK326268, MK326384, MK326117, MK326344, MK326305, MK326079, MK326210. C. rileyi (Wiehler) J. F. Smith, J. F. Smith 1944, WIS, Ecuador, KF005885, KF006101, KF005994, KF006202, KF005706, KF005791, MK326212. C. rileyi (Wiehler) J. F. Smith, J. L. Clark 6263, US, Ecuador, KF005886, KF006102, KF005995, KF006203, DQ211250, AF543239, MK326213. C. rubricalyx L. P. Kvist \& L. E. Skog, J. L. Clark et al. 11034, UNA, Ecuador, KF005887, KF006103, KF005997, KF006204, KF005707, KF005792, MK326214. C. rubricalyx L. P. Kvist \& L. E. Skog, T. Croat 95236, MO, Ecuador, KF005888, KF006104, KF005996, KF006205, KF005708, KF005793, MK326215. C. rutilans Sw., J. F. Smith et al. 10046, SRP, Jamaica, MK326269, MK326385, MK326118, MK326345, MK326306, MK326080, MK326216. C. rutilans Sw., J. F. Smith et al. 10053, SRP, Jamaica, MK326270, MK326386, MK326119, MK326346, MK326307, MK326081, MK326217. C. sanguinea (Pers.) Hanst., L. A. Hahn et al. 410, SRP, Dominican Republic, MK326272, MK326388, MK326121, MK326348, MK326309, MK326083, MK326224. C. sanguinea (Pers.) Hanst., J. F. Smith 636, WIS, cultivated, KF005889, KF006105, KF005998, KF006206, KF005709, KF005794, MK326218. C. scandens L., J. L. Clark \& S. G. Clark 6541, UNA, Martinique, KF005890, KF006106, KF005999, KF006207, KF005711, KF005792, MK326219. C. scandens L., J. L. Clark \& J. Katzenstein 8879, US, Cultivated, MK326271, MK326387, MK326120, MK326347, MK326308, MK326082, MK326220. C. schiedeana Schldtl., J. F. Smith 288, WIS, Cultivated, originally from Mexico, KF005891, KF006107, KF006000, KF006208, KF005712, KF0057967, MK326221. C. schimpfii Mansf., J. F. Smith 8603, SRP, Cultivated, originally form Ecuador, KF005892, KF006109, KF006001, KF006209, KF005713, KF005797, MK326222. C. segregata (B. D. Morley) Wiehler, J. L. Clark et al. 10029, UNA, cultivated, KF554378, KF006108, KF006002, KF006210, KF005714, KF554337, MK326223. C. spathulata Mansf., J. L. Clark et al. 7485, UNA, Ecuador, KF005894, KF006111, KF006004, KF006212, KF005716, KF005799, MK326226. C. spathulata Mansf., J. F. Smith 1853, WIS, Ecuador, KF005893, KF006110, KF006003, KF006211, KF005715, KF005798, MK326225. C. strigosa Benth., T. Croat 94580, MO, Ecuador, KF005896, KF006113, KF006006, KF006213, KF005718, KF005801, MK326228. C. strigosa Benth., J. F. Smith 1200, WIS, Venezuela, KF005895, KF006112, KF006005, KF006214, KF005717, KF005800, MK326227. C. subcordata C. V. Morton, no voucher IPEN \# XXOG20110726, NA, Cultivate, originally from Jamaica, MK326273, MK326389, MK326122, MK326349, MK326310, MK326084, MK326229. C. tenella L. P. Kvist \& L. E. Skog, M. Amaya Marquez \& J. F. Smith 603, COL, Colombia, KF005897, KF006114, KF006007, KF006215, KF005719, KF005802, MK326230. C. tenensis Wiehler, J. L. Clark et al. 9500, UNA, Ecuador, KF005899, KF006116, KF006009, KF006217, KF005721, KF005803, MK326232. C. tenensis Wiehler, J. F. Smith \& R. W. Dunn 3374, SRP, Ecuador, KF005898, KF006115, KF006008, KF006216, KF005720, KF005804, MK326231. C. tincta, J. L. Clark 15062, UNA, Cuba, MK326274, MK326390, MK326123, MK326350, MK326311, NA, MK326233. C. trollii Mansf., J. F. Smith 1723, WIS, Bolivia, KF005899, KF006117, KF006010, KF006218, KF005722, KF005805, MK326234. C. ultraviolacea J. F. Smith \& L. E. Skog, J. L. Clark \& V. Velaz 6603, UNA, Bolivia, KF005900, KF006118, KF006011, KF006219, KF005723, KF005806, MK326235. C. urbanii Stearn, J. F. Smith et al. 10045, SRP, Jamaica, MK326275, MK326391, MK326124, MK326351, MK326312, MK326085, MK326236.

Outgroup: Glossoloma anomalum J. L. Clark, J. F. Smith 3418, SRP, Ecuador, KF005912, KF006128, KF006021, KF006224, NA, AF543225, MK326125. Glossoloma grandicalyx (J. L. Clark \& L. E. Skog) J. L. Clark, J. F. Smith 3417, SRP, Ecuador, KF005913, KF006129, KF006024, JQ953708, DQ211205, AF543218, MK326126. Glossoloma martinianum (J. F. Smith) J. L. Clark, J. L. Clark 6101, US, Ecuador, KF005914, KF006130, KF006022, JQ953709, DQ211209, AF543228, MK326127. Glossoloma panamense (C. V. Morton) J. L. Clark, L. E. Skog et al. 7641, US, cultivated, KF005915, KF006131, KF006023, JQ953710, DQ211202, DQ211102, MK326128. 


\section{Literature Cited}

Acevedo-Rodriguez P, MT Strong 2008 Floristic richness and affinities in the West Indies. Bot Rev 74:5-36.

2017 Flora of the West Indies. 2017 http://botany.si.edu /antilles/WestIndies/index.htm.

Arden DD Jr 1975 Geology of Jamaica and the Nicaraguan rise. Pages 627-661 in AEM Nairn, FG Stehli, eds. The Gulf of Mexico and the Caribbean. Springer, New York.

Baldwin BG, DW Kyhos, J Dvořák, GD Carr 1990 Chloroplast DNA evolution and adaptive radiation in the Hawaiian silversword alliance (Madiinae: Asteraceae). Ann Mo Bot Gard 77:96-109.

Baldwin BG, S Markos 1998 Phylogenetic utility of the external transcribed spacer (ETS) of 18S-26S rDNA: congruence of ETS and ITS trees of Calycadenia. Mol Phylogenet Evol 10:449-463.

1991 Chloroplast DNA evidence for a North American origin of the Hawaiian silversword alliance (Madiinae, Asteraceae). Proc Natl Acad Sci USA 88:1840-1843.

Bauret L, M Gaudeul, MA Sundue, BS Parris, TA Ranker, F Rakotondrainibe, S Hennequin, J Ranaivo, M-A Selosse, G Rouhan 2017 Madagascar sheds new light on the molecular systematics and biogeography of grammitid ferns: new unexpected lineages and numerous long-distance dispersal events. Mol Phylogenet Evol 111:1-17.

Berazaín Iturralde R 2001 The influence of ultramafic soils on plants in Cuba. South Afr J Sci 97:510-512.

Blake JG, BA Loiselle 1992 Fruits in the diets of Neotropical migrant birds in Costa Rica. Biotropica 24:200-210.

Borhidi A 1991 Phytogeograpy and vegetation ecology of Cuba. Akadémiai Kiadó, Budapest, Hungary.

Brongniart A 1828 Considérations générale sur la nature de la végétation qui couvrait la surface de la terre aux diverse époques de formation de son écorce. Annale des Sciences Naturelles. Vol 15. Crochard, Paris.

Brundin L 1972 Phylogenetics and biogeography. Syst Zool 21:6979.

Buerki S, DS Devey, MW Callmander, PB Phillipson, F Forest 2008 Spatio-temporal history of the endemic genera of Madagascar. Bot J Linn Soc 171:1095-8339.

Bush GL, SM Case AC Wilson JL Patton 1977 Rapid speciation and chromosomal evolution in mammals. Proc Natl Acad Sci USA 74:3942-3946.

Buskirk RE 1985 Zoogeographic patterns and tectonic history of Jamaica and the Northern Caribbean. J Biogeogr 12:445-461.

Callmander MW, PB Phillipson, GM Plunkett, MB Edwards, S Buerki 2016 Generic delimitations, biogeography and evolution in the tribe Coleeae (Bignoniaceae), endemic to Madagascar and the smaller islands of the western Indian Ocean. Mol Phylogenet Evol 96:178186.

Campbell HJ, CA Landis 2003 New Zealand awash. New Zealand Geographic 2003:6-7.

Carlquist S 1965 Island life. Natural History Press, New York.

Charlesworth B, D Charlesworth 1997 Rapid fixation of deleterious alleles can be caused by Muller's ratchet. Genet Res 70:63-73.

Clark JR, RH Ree, ME Alfaro, MG King, WL Wagner, EH Roalson 2008 A comparative study in ancestral range reconstruction methods: retracing the uncertain histories of insular lineages. Syst Biol 57:693-707.

Cracraft J 1973 Continental drift, paleoclimatology, and the evolution and biogeography of birds. J Zool Lond 169:455-545.

Crews SC, RG Gillespie 2010 Molecular systematics of Selenops spiders (Araneae: Selenopidae) from North and Central America: implications for Caribbean biogeography. Biol J Linn Soc 101:288-322.

Cronk QCB, M Kiehn, WL Wagner, JF Smith 2005 Evolution of Cyrtandra (Gesneriaceae) in the Pacific Ocean: the origin of a supertramp clade. Am J Bot 92:1017-1024.
Darriba D, GL Taboada, R Doallo, D Posada 2012 jModelTest 2: more models, new heuristics and parallel computing. Nat Meth 9: 772.

Darwin C 1839 Narrative of the surveying voyage of His Majesty's ships Adventure and Beagle between the years 1826 and 1836, describing their examination of the shores of South America and the Beagle's circumnavigation of the globe. Henry Colbum, London.

Downer A, R Sutton 1990 Birds of Jamaica. Cambridge University Press, Cambridge.

Fritsch K 1894 Gesneriaceae. Pages 133-184 in A Engler, K Prantl, eds. Die Natürlichen Pflanzenfamilien. 4(3b). Verlag Engelmann, Leipzig, Germany.

Fritsch PW 2003 Multiple geographic origins of Antillean Styrax. Syst Bot 28:421-430.

Fritsch PW, TD McDowell 2003 Biogeography and phylogeny of Caribbean plants: introduction. Syst Bot 28:376-377.

Garrido OH, A Kirkconnell 2000 Field guide to the birds of Cuba. Comstock Publications, Ithaca, NY.

Gauthier N 2010 Multiple cryptic genetic units in Hypothenemus hampei (Coleoptera: Scolytinae): evidence from microsatellite and mitochondrial DNA sequence data. Biol J Linn Soc 101:113-129.

Gemmill CEC, GJ Allan, WL Wagner, EA Zimmer 2002 Evolution of insular Pacific Pittosporum (Pittosporaceae): origin of the $\mathrm{Ha}$ waiian radiation. Mol Phylogenet Evol 22:31-42.

Gillespie RG, HB Croom 1995 Comparison of speciation mechanisms in web-building and non-web-building groups within a lineage of spiders. Pages 121-146 in WL Wagner, VA Funk, eds. Hawaiian Biogeography. Evolution on a hot spot archipelago. Smithsonian Institution, Washington, DC.

Givnish TJ, KJ Sytsma 2000 Molecular evolution and adaptive radiation. Cambridge University Press, Cambridge.

Givnish TJ, KJ Sytsma, JF Smith, WJ Hahn 1995 Molecular evolution, adaptive radiation, and geographic speciation in Cyanea (Campanulaceae, Lobelioideae). Pages 288-337 in WL Wagner, VA Funk, eds., Hawaiian Biogeography. Evolution on a hot spot archipelago. Smithsonian Institution, Washington, DC.

Gostel MR, PB Phillipson, A Weeks 2016 Area phylogenetic reconstruction of the myrrh genus, Commiphora (Burseraceae), reveals multiple radiations in Madagascar and clarifies infrageneric relationships. Syst Bot 41:67-81.

Gostel MR, GM Plunkett, PP Lowry II 2016 Straddling the Mozambique Channel: molecular evidence for two major clades of AfroMalagasy Schefflera (Araliaceae) co-occurring in Africa and Madagascar. Plant Ecol Evol 150:87-108.

Graham A 2003 Geohistory models and Cenozoic paleoenvironments of the Caribbean region. Syst Bot 28:378-386.

Grandcolas P, J Murienne, T Robillard, L Desutter-Grandcolas, H Jourdan, E Guilbert, L Deharveng 2008 New Caledonia: a very old Darwinian island? Philos Trans R Soc B 363:3309-3317.

Heads M 2008 Panbiogeography of New Caledonia, south-west Pacific: basal angiosperms on basement terranes, ultramafic endemics inherited from volcanic island arcs and old taxa endemic to young islands. J Biogeogr 35:1365-2699.

Hillis DM, C Moritz 1990 Molecular systematics. Sinauer Associates, Sunderland, MA.

Hedges SB 2006 Paleogeography of the Antilles and origin of West Indian terrestrial vertebrates. Ann Mo Bot Gard 93:231-244.

Hedges SB, K Burnell 1990 The Jamaican radiation of Anolis (Sauria: Iguanidae): an analysis of relationships and biogeography using sequential electrophoresis. Caribb J Sci 26:31-44.

Heinicke MP, WE Duellman, SB Hedges 2007 Major Caribbean and Central American frog faunas originated by ancient oceanic dispersal. Proc Natl Acad Sci USA 104:10092-10097. 
Huxley TH 1868 On the classification and distribution of the Alectoromorphae and Heteromorphae. Proc Zool Soc Lond 1868:294-319. Irimia R-E, AP Oscar, M Gottschling 2015 Strong biogeographic signal in the phylogenetic relationships of Rochefortia Sw. (Ehretiaceae, Boraginales). Plant Syst Evol 301:1509-1516.

Iturralde-Vinent, MA, RDE MacPhee 1999 Paleogeography of the Caribbean region: implications for Cenozoic biogeography. Bull Am Mus Nat Hist 238:1-95.

Joseph L, T Wilke, E Bermingham, D Alpers, R Ricklefs 2004 Towards a phylogenetic framework for the evolution of shakes, rattles and rolls in Myiarchus tryant-flycatchers (Aves: Passeriformes: Tyrannidae). Mol Phylogenet Evol 31:139-152.

Kumar S, G Stecher, K Tamura 2016 MEGA7: molecular evolutionary genetics analysis version 7.0 for bigger datasets. Mol Biol Evol 33:1870-1874.

Kruckeberg A 1986 An essay: the stimulus of unusual geologies for plant speciation. Syst Bot 11:455-463.

Kvist LP, LE Skog 1992 The genus Columnea (Gesneriaceae) in Ecuador. Allertonia 6:327-400.

Ladiges PY, D Cantrill 2007 New Caledonia-Australian connections: biogeographic patterns and geology. Aust Syst Bot 20:383-389.

Latta S, C Rimmer, A Keith, J Wiley, HA Raffaele, K McFarland, E Fernandez 2010 Birds of the Dominican Republic and Haiti. Princeton University Press, Princeton, NJ.

Lavin M, AB Matos 2008 The impact of ecology and biogeography on legume diversity, endemism, and phylogeny in the Caribbean region: a new direction in historical biogeography. Bot Rev 74:178-196.

MacArthur RH, EO Wilson 1963 An equilibrium theory of insular zoography. Evolution 17:373-387.

1967 The theory of island biogeography. Monographs in population biology. No. 1. Princeton University Press, Princeton, NJ.

Matos-Moraví P, RN Águila, C Peña, JY Miller, A Sourakov, N Wahlberg 2014 Causes of endemic radiation in the Caribbean: evidence from the historical biogeography and diversification of the butterfly genus Calisto (Nymphalidae: Satyrinae: Satyrini). BMC Evol Biol 14:199.

Matzke NJ 2013 BioGeoBEARS: biogeography with Bayesian (and likelihood) evolutionary analysis in $\mathrm{R}$ scripts. $\mathrm{R}$ package, version 0.2 1. R Foundation for Statistical Computing, Vienna.

Miller MA, W Pfeiffer, T Schwartz 2010 Creating the CIPRES science gateway for inference of large phylogenetic trees. Proceedings of the Gateway Computing Environments Workshop, New Orleans.

Möller M, JL Clark 2013 The state of molecular studies in the family Gesneriaceae: a review. Selbyana 31:95-125.

Molnar P, T Atwater, J Mammerycx, SM Smith 1975 Magnetic anomalies, bathymetry and the tectonic evolution of the South Pacific since the late Cretaceous. Geophys J Int 40:383-420.

Morley BD 1971 A hybrid swarm between two hummingbirdpollinated species of Columnea (Gesneriaceae) in Jamaica. J Linn Soc Bot 64:81-96.

1972 The distribution and variation of some gesneriads on Caribbean islands. Pages 239-257 in DH Valentine, ed. Taxonomy phytogeography and evolution. Academic Press, New York.

1974 A revision of the Caribbean species in the genera Columnea L. and Alloplectus Mart. (Gesneriaceae). Proc R Ir Acad 74:411-438.

1976 Hybridization studies in Columnea L. (Gesneriaceae). 1. Jamaican species. Bot J Linn Soc 72:191-198.

Müller K 2004 PRAP: computation of Bremer support for large data sets. Mol Phylogenet Evol 31:780-782.

Müller J, K Müller, C Neinhuis, D Quandt 2010 PhyDE version 0.9971. http://www.phyde.de/.

Negron-Ortiz V, LE Watson 2003 Molecular phylogeny and biogeography of Erithalis (Rubiaceae), an endemic of the Caribbean basin. Plant Syst Evol 234:71-83.
Nelson G, NI Platnick 1981 Systematics and biogeography. Cladistics and vicariance. Columbia University Press, New York.

Oneal E, D Otte, LL Knowles 2010 Testing for biogeographic mechanisms promoting divergence in Caribbean crickets (genus Amphiacusta). J Biogeogr 37:530-540.

Peck SG 1997 Historical biogeography of Jamaica: evidence from cave invertebrates. Can J Zool 77:368-380.

Platnick NI, G Nelson 1978 A method of analysis for historical biogeography. Syst Zool 27:1-16.

Proctor M, P Yeo, A Lack 1996 The natural history of pollination. Timber Press, Portland, OR.

Rambaut A, MA Suchard, D Xie, AJ Drummond 2014 Tracer v1.6. http://beast.bio.ed.ac.uk/Tracer.

Raven PH, DI Axelrod 1974 Angiosperm biogeography and past continental movements. Ann Mo Bot Gard 61:539-673.

Ree RH, SA Smith 2008 Lagrange: software for likelihood analysis of geographic range evolution. Syst Biol 57:4-14.

Richerson PJ, K-L Lum 1980 Patterns of plant species diversity in California: relation to weather and topography. Am Nat 116:504-536.

Roalson EH, WR Roberts 2016 Distinct processes drive diversification in different clades of Gesneriaceae. Syst Biol 65:662-684.

Roalson EH, LE Skog, EA Zimmer 2008 Untangling Gloxinieae (Gesneriaceae). II. Reconstructing biogeographic patterns and estimating divergence times among New World continental and island lineages. Syst Bot 33:159-175.

Rodríguez A, M Vences, B Nevado, A Machordom, E Verheyen 2010 Biogeographic origin and radiation of Cuban Eleutherodactylus frogs of the auriculatus species group, inferred from mitochondrial and nuclear gene sequences. Mol Phylogenet Evol 54:179-186.

Roncal J, S Zona, CE Lewis 2008 Molecular phylogenetic studies of Caribbean palms (Arecaceae) and their relationships to biogeography and conservation. Bot Rev 74:78-102.

Ronquist F, D Cannatella 1997 Dispersal-vicariance analysis: a new approach to the quantification of historical biogeography. Syst Biol 46:195-203.

Ronquist F, M Teslenko, P van der Mark, DL Ayres, A Darling, S Höhna, B Larget, L Liu, M Suchard, JP Huelsenbeck 2012 MrBayes 3.2: efficient Bayesian phylogenetic inference and model choice across a large model space. Syst Biol 61:539-542.

Rosen DE 1978 Vicariant patterns and historical explanation in biogeography. Syst Zool 27:159-188.

Salzman VT, WS Judd 1995 A revision of the greater Antillean species of Bactris (Bactridinae: Arecaceae). Brittonia 46:345-371.

Santiago-Valentin E, RG Olmstead 2004 Historical biogeography of Caribbean plants: introduction to current knowledge and possibilities from a phylogenetic perspective. Taxon 53:299-319.

Schouw JF 1823 Grundzüge einer allgemeinene Pflanzengeographie. Reimer, Berlin.

Schubart CD, R Diesel, SB Hedges 1998 Rapid evolution to terrestrial life in Jamaican crabs. Nature 393:363-365.

Schulte LJ, JL Clark, SJ Novak, MT-Y Ooi, JF Smith 2014 Paraphyly of section Stygnanthe (Columnea, Gesneriaceae), a new section inferred from ITS and chloroplast DNA data, and a revision of the species of section Angustiflorae. Syst Bot 39:613-636.

Schulte LJ, JL Clark, SJ Novak, SK Jeffries, JF Smith 2015 Speciation within Columnea section Angustiflorae (Gesneriaceae): islands, pollinators and climate. Mol Phylogenet Evol 84:125-144.

Sclater PL 1858 On the general geographical distribution of the members of the class Aves. Zool J Linn Soc 2:130-145.

Seutin G, NK Klein, RE Ricklefs, E Bermigham 1994 Historical biogeography of the bananaquit (Coereba flaveola) in the Caribbean region: a mitochondrial DNA assessment. Evolution 48:1041-1061.

SELVA 2017 Crossing the Caribbean: Neotropical migratory birds in northern Colombia (April 2009-present). http://selva.org.co/research -programs/migratory-species/crossing-the-caribbean/. 
Shimodaira H 2002 An approximately unbiased test of phylogenetic tree selection. Syst Biol 51:492-508.

Shimodaira H, M Hasegawa 2001 CONSEL: for assessing the confidence of phylogenetic tree selection. Bioinformatics 17:1246-1247.

Skog LE 1976 A study of the tribe Gesnerieae, with a revision of Gesneria (Gesneriaceae: Gesnerioideae). Smithson Contrib Bot 29:1182.

Slatkin M 1987 Gene flow and the geographic structure of natural populations. Science 236:787-793.

Smith JF 1994 Systematics of Columnea sections Pentadenia and Stygnanthe (Gesneriaceae). Syst Bot Monogr 44:1-89.

Smith JF, JL Clark, M Amaya-Márquez, OH Marín-Gómez 2017 Resolving incongruence: species of hybrid origin in Columnea (Gesneriaceae). Mol Phylogenet Evol 106:228-240.

Smith JF, MT-Y Ooi, JL Clark 2018 Incipient speciation in a neotropical Gesneriaceae: Columnea kucyniakii is nested within C. strigosa. Plant Syst Evol 304:511-519.

Smith JF, MT-Y Ooi, LJ Schulte, M Amaya-Marquez, JL Clark 2013 Searching for monophyly in the subgeneric classification systems of Columnea (Gesneriaceae). Selbyana 31:126-142.

Smith SA, RA Sadlier, AM Bauer, CC Austin, T Jackman 2007 Molecular phylogeny of the scincid lizards of New Caledonia and adjacent areas: evidence for a single origin of the endemic skinks of Tasmantis. Mol Phylogenet Evol 43:1151-1166.

Stamatakis A 2006 RAxML-VI-HPC: maximum likelihood-based phylogenetic analyses with thousands of taxa and mixed models. Bioinformatics 22:2688-2690.

Stearn WT 1968 Observations on a computer-aided survey of the Jamaican species of Columnea and Alloplectus. Pages 219-224 in VH Heywood, ed. Modern methods in plant taxonomy. Academic Press, New York.

Steinbauer MJ, R Field, JA Grytnes, P Trigas, C Ah-Peng, F Attorre, HJB Birks, et al 2016 Topography-driven isolation, speciation and a global increase of endemism with elevation. Glob Ecol Biogeogr 25:1097-1107.

Swainson W 1835 A treatise on the geography and classification of animals. Longman, London.

Swenson U, J Munzinger, IV Bartish 2007 Molecular phylogeny of Planchonella (Sapotaceae) and eight new species from New Caledonia. Taxon 56:329-354.

Swofford DE 2002 PAUP*. Phylogenetic analysis using parsimony ("and other methods). Sinauer Associates, Sunderland, MA.

Tarr CL, RC Fleisher 1995 Evolutionary relationships of the Hawaiian honeycreepers (Aves, Drepanidinae). Pages 147-159 in WL Wagner, VA Funk, eds. Hawaiian biogeography. Evolution on a hot spot archipelago. Smithsonian Institution, Washington DC.

Trewick SA 1997 Sympatric flightless rails Gallirallus dieffenbachii and G. modestus on the Chatham Islands, New Zealand: morphometrics and alternative evolutionary scenarios. J R Soc N Z 27:451-464.
Urban I 1901 Enumeratio Gesneriacearum. Symb Antill 2:344-388. Van Ee BW, PE Berry 2009 A phylogenetic and taxonomic review of Croton (Euphorbiaceae s. s.) on Jamaica including description of Croton jamaicensis, a new species of section Eluteria. Syst Bot 34:129-140.

von Hagen KB, J Kadereit 2001 The phylogeny of Gentianella (Gentianaceae) and its colonization of the southern hemisphere are revealed by nuclear and chloroplast DNA sequence variation. Org Divers Evol 1:61-79.

von Humboldt A 1805 Essai sur la géographie des plantes. Theatrum Orbis Terrarum Limited, Paris.

Wagstaff SJ, PJ Garnock-Jones 1998 Evolution and biogeography of the Hebe complex (Scrophulariaceae) inferred from ITS sequences. N Z J Bot 36:425-437.

Wallace AR 1860 On the zoological geography of the Malay Archipelago. J Linn Soc Lond 4:172-184.

1869 The Malay Archipelago: the land of the orangutan, and the bird of paradise. Harper, New York.

- 1876 The geographical distribution of animals. Vol 2. Macmillan, London.

1880 Island life, or the phenomena and causes of insular faunas and floras. Macmillan, London.

Weaver PF, A Cruz, S Johnson, J Dupin, KF Weaver 2016 Colonizing the Caribbean: biogeography and evolution of livebearing fishes of the genus Limia (Poeciliidae). J Biogeogr 43:1808-1819.

Weber A, JL Clark, M Möller 2013 A new formal classification of Gesneriaceae. Selbyana 31:68-94.

Whittaker RJ, KA Triantis, A Kostas, RJ Ladle 2008 A general dynamic theory of oceanic island biogeography. J Biogeogr 35:1365-2699.

Wiehler H 1973 One hundred transfers from Alloplectus and Columnea. Phytologia 27:309-329.

1975 Name changes in Neotropical Gesneriaceae. Selbyana 1:32-35.

_ 1983 A synopsis of the Neotropical Gesneriaceae. Selbyana 6:1-219.

Winkworth RC, S Wagstaff, D Glenny, PJ Lockhart 2002 Plant dispersal N.E.W.S. from New Zealand. Trends Ecol Evol 17:514-520.

Woo VL, JF Smith, MM Funke, PJ Lockhart, PJ Garnock-Jones 2011 Phylogenetic relationships in Coronanthereae (Gesneriaceae) reveal multiple introductions from South America into the Pacific. Int J Plant Sci 172:434-457.

Wunderle JM, RB Waide 1993 Distribution of overwintering Nearctic migrants in the Bahamas and Greater Antilles. Condor 95:904-33.

Yoder AD, MD Nowak 2006 Has vicariance or dispersal been the predominant biogeographic force in Madagascar? only time will tell. Annu Rev Ecol Evol Syst 37:405-431.

Yu Y, AJ Harris, X He 2010 S-DIVA (statistical dispersal-vicariance analysis): a tool for inferring biogeographic histories. Mol Phylogenet Evol 56:848-850. 